\title{
Recuerdos de Pedro Henríquez Ureña
}

F NTRE el polvo y la ceniza del tiempo la luz de estos recuerdos. Primero, en Nueva York (1918), a través del entusiasmo de Salomón de la Selva, su amigo predilecto. Después, el contacto más directo, epistolar, de Pedro, en su soledad de Minnesota donde preparaba ya su sólida obra sobre La Versificación irregular. Entre la nieve de Minneapolis y el helado viento de Nueva York la vibración cordial de nuestra amistad. Cuando Pedro abandonó ese ambiente gélido, por dentro $\mathrm{y}$ por fuera, yo iba a sucederle en la cátedra y a dictar por primera vez (1921) un curso de literatura hispanoamericana. El nombre de Pedro estaba allí presente, vivo entre las papeletas de un seminario que buscaba "los elementos líricos en el drama español anterior a Lope de Vega", vivo también en el afecto de Antonio Heras; en la admiración de unos cuantos estudiantes. El profesor Beach me preguntaba constantemente por Pedro, su amigo tan querido de esos años. Más tarde, en 1922, Pedro me invitó a los cursos de verano de la Universidad de México. Allí estuve por unas semanas cerca de su espíritu y de su visión. Allí escuché su palabra mesurada, serena, profunda y sabia. Charlas en su despacho de la vieja universidad, en los pasillos, en las salas de clase, visitas a su amable casa en un lejano barrio de México, conversaciones y refrigerios bajo la mirada tutelar de una culta anciana, creo que tía suya; gratas charlas en compañía de Cosío Villegas, Alejandro Villaseñor, Julio Jiménez Rueda, Salvador Novo, Jaime Torres Bodet. Las comidas en el viejo restaurante "Colón", junto a José Vasconcelos, Julio Torri, Pellicer. 
Es problable que ya nadie recuerde una discusión entre el ático Henríquez Ureña y el exaltado Vasconcelos, para mí tan gestora. Vasconcelos, que acababa de invitar a Gabriela Mistral a México, hablaba de "Ia única poetisa de América"; Pedro le recordó el nombre de Juana de Ibarbourou. Vasconcelos, con apasionado gesto, dijo: "todavía hay categorías, Pedro". Así quedaron definidos ante mí los dos grandes es. critores.

Pedro partió en viaje a la América del Sur ese verano en compañía de Vasconcelos, Antonio Caso, Julio Torri y otros intelectuales mexicanos. Para mí la Universidad quedó semidesierta.

Veinte años de silencio. En 1943 vi a Pedro por última vez en Buenos Aires. A pesar de sus muchos éxitos le encontré desencantado y triste. Hablamos varias veces en el Instituto de Filología, y recordamos los que a él le gustaba llamar "nuestros días alcióneos". Con Amado Alonso y Angel Rosenblat bajamos algunas tardes a tomar un refresco. Un día de enero de 1944 vi por última vez a Pedro. Le dejé en una esquina de la Avenida de Mayo y le observé cruzar la calle, con andar fatigado, en su traje negro de siempre. No sé por qué me invadió una gran tristeza esa tarde.

En 1918 la reputación de Pedro Henríquez Ureña, según entendí yo en Nueva York, era de una solidez reconocida entre la gente de los países del Norte de nuestra América. Ya había publicado sus Ensayos criticos en La Habana (1905), sus Horas de estudio en París (1910), su conferencia sobre Juan Ruiz de Alarcón en México (1914), su estudio sobre el maestro Hernán Pérez de Oliva en Cuba (1914), su tragedia clásica El nacimiento de Dionisos en Nueva York (1916), su Literatura dominicana en París (1917). Preparaba entonces su tesis doctoral La versificación irregular en la poesía castellana que iba a publicar poco después en Madrid (1920). Por Salomón de la Selva conocí yo El Nacimiento de Dionisos, obra de cultura más que de inspiración, de rigurosa exactitud preceptista. Salomón tenía dos dioses mayores: Rubén Darío y Pedro Henríquez Ureña. Un dominicano avecindado en la gran cosmópolis, hombre de letras y de fiesta, Manuel Cestero, consideraba a Pedro como un maestro. Muñoz Marín, Requena 
Legarreta, René Borgia seguían con admiración y cariño la labor del profesor de Minnesota. En verdad Pedro era ya el maestro continuador de la obra de José Enrique Rodó. Sus intereses en materias intelectuales eran múltiples; filología, historia, crítica literaria, filosofía, gramática, métrica, pedagogía, estudios clásicos. Yo leí con creciente admiración toda su obra y tengo aquí frente a mis ojos un ejemplar de $E l$ Nacimiento de Dionisos con esta dedicatoria: "Al profesor Peter H. Goldschmidt, atentamente, Pedro Henriquez Ureña, N. Y., Feb. 1916". Este señor Goldschmidt era una buen varón que editaba una famosa revista en los dos idiomas en Nueva York.

Además de sus estudios sobre literaturas hispánicas, Pedro había divulgado ya algunos destacados valores de la literatura inglesa tales como Walter Pater, Oscar Wilde, Bernard Shaw. Leía con gran interés en esos días a los escritores norteamericanos. En mi ensayo La influencia de los Estados Unidos en nuestra literatura ("Cuadernos", París, Julio-Agosto, 1956) yo digo lo siguiente: "Pedro Henríquez Ureña era una autoridad en la materia. Creo que en su tiempo nadie conoció mejor que él las letras norteamericanas. Ya en 1909 escribe un comentario sobre el dramaturgo yanqui Clyde Fitch, incluído en su libro Horas de estudio. Durante su estada en los Estados Unidos escribió acerca de Edith Warton, Vachel Lindsay, William Rose Benet, Edna St. Vincent Millay. Su artículo Veinte años de literatura en los Estados Unidos ("Nosotros", LVII, 1927) es el mejor comentario sintético que se ha hecho de la literatura norteamericana en el primer cuarto del siglo presente".

No hay más que leer su libro Literary currents in Hispanic America (Harvard University Press, 1945) para observar los profundos conocimientos de Pedro en este campo.

Hasta aquí lo que yo sabía de Pedro en mi primera aproximación a él. Más tarde le seguí en su desarrollo intelectual a través de sus obras mayores: En la orilla: mi España (México, 1922), Seis ensayos en busca de nuestra expresión (Buenos Aires, 1928), Sobre el problema del andalucismo dialectal de América (Buenos Aires, 1932), La cultura y las letras coloniales en Santo Domingo (Buenos Aires, 1936), Plenitud de España (Buenos Aires, 1940). 
Todo esto me llenaba de orgullo, en parte por motivos egoístamente personales. Pedro había sido una especie de padrino literario para mí. El fue quien por primera vez comentó mis poemas de juventud en su cátedra; él me recomendó para que le sucediera en su puesto de la Universidad de Minnesota; él quien me invitó a dar clases en la Universidad de México; él quien me presentó a los maestros mexicanos, Antonio Caso, José Vasconcelos, Julio Torri. A esta distancia —diez años de su muerte- su recuerdo está vivo, por el afecto, por la admiración, por la nobleza del ejemplo.

Ahora que el nombre de Pedro Henríquez Ureña ha entrado en la historia, esta humilde nostalgia mía es el homenaje que le rinde mi recuerdo.

\author{
ARturo TORRes Rf́oseco \\ Universidad de California, \\ Berkeley.
}

